$(\mathrm{OR}=2,763, \mathrm{p}=0,009)$, tân suất cơn $>1$ cơn/tháng $(O R=9,612, p<0,001)$, đa trị liệu $(\mathrm{OR}=4,097, p<0,001)$. Các yếu tố khác như nơi ở, trình độ học vấn, số năm bị bệnh động kinh không ảnh hưởng tới việc mắc rối loạn trầm cảm. Không có yếu tố nào làm tăng mức độ rối loạn trầm cảm có ý nghĩa thống kê

\section{TÀI LIÊU THAM KHẢO}

1. Neligan, A., W.A. Hauser, and J.W. Sander, The epidemiology of the epilepsies. Handb Clin Neurol, 2012. 107: p. 113-33.

2. Miller, J.M., et al., Depressive Symptoms in Epilepsy Prevalence, Impact, Aetiology, Biological Correlates and Effect of Treatment with Antiepileptic Drugs. 2008.
3. Mazza, M., P. Bria, and S. Mazza, Depression and suicide in epilepsy: fact or artefact? J Neurol Sci, 2007. 260(1-2): p. 300-1.

4. Gupta, S., et al., Depression and anxiety in patients with epilepsy. International Journal of Advances in Medicine, 2018. 5(5): p. 1268.

5. Berhanu Boru Bifftu, B.A.D., Bewket Tadesse Tiruneh and Nigusie Birhan Tebeje, Depression among people with epilepsy in Northwest Ethiopia: a cross-sectional institution based study. 2015.

6. Triantafyllou, N.I., et al., Patterns of depressive symptoms in epilepsy. 2012.

7. Kumar, $\mathbf{N}_{\text {., }}$ et al., Depressive Symptom Severity in Individuals With Epilepsy and Recent Health Complications. J Nerv Ment Dis, 2019. 207(4): p. 284-290.

8. Nair, P.P.C., S. C. Menon, V. Wadwekar, V., High Frequency of Depressive Symptoms among Adults with Epilepsy: Results from a Hospital-based Study. J Neurosa Rural Pract, 2017. 8(Suppl 1): p. S13-S19.

\title{
CHẨN ĐOÁN HIỄU ỨNG ÁO CHOÀNG TRẮNG BẰNG HOLTER HUYẾT ÁP 30 PHÚT
}

\author{
Châu Hưu Hầu*, Hia Kim Khuê*, Quách Lâm Thanh Trúc*
}

\section{TÓM TẮT}

Nghiên cứu có mục tiêu xác định và loại trừ hiêuu ứng tăng huyết áp áo choàng trắng bằng đo huyết ảp lưu động 30 phút tại tuyến y tế cơ sở. Đối tượng nghiên cứu: Bệnh nhân đến khám tại các buồng khám thuộc Khoa Khám bệnh của bệnh viện Nhật Tân thành phố Châu Đốc, trong 8 tháng từ 1/10/2020 cho đến $31 / 5 / 2021$, có tăng huyết áp mà bác sĩ khám nghĩ đến hiệu ứng áo choàng trắng. Số bản ghi kết quả đo huyết áp lưu động ít nhất 8 lần trong 30 phút là 163. Phương pháp nghiên cứu: Thuần tập với Holter $\mathrm{HA}$ hiệu Norav, NBP-24 NG; có phân tích so sánh kết quả về tân số tăng huyết áp giữa các phương pháp đo. Kết quả: Tổng số có 163 người được ghi huyết áp lưu động 30 phút đây đủ, trong đó nữ 93 , chiếm $57 \%$; tuổi từ 14 đến 86, trung bình là 48,7 $\pm 14,5$. Kết quá đo huyết áp tại buồng khám cho thấy: Bác sĩ chẩn đoán có 107 người mắc tăng huyết áp $(65,6 \%)$. Tuy nhiên sau khi có kết quả đo huyết áp lưu động 30 phút, số bệnh nhân thực sự cần điều trị tăng huyết áp chi còn 74 người $(45,4 \%)$, giảm 33 người $(20,2 \%)$. Kết luận: Nghiên cứu cho thấy phương pháp đo huyết áp lưu động 30 phút giúp phát hiện và giảm hiệu ứng tăng huyết áp áo choàng trắng khoảng $20,2 \%$ trong số được chẩn đoán tăng huyết áp tại buồng khám, qua đó giúp chẩn đoán người bệnh tăng huyết áp thực sự sau khi loại trừ tăng huyết áp áo choàng trắng, góp phân giảm chi phí, tác dụng phụ và

*Bệnh viện Nhật Tân

Chịu trách nhiệm chính: Châu Hữu Hầu

Email: benhviennhattan@gmail.com

Ngày nhận bài: 9.7.2021

Ngày phản biện khoa họ: 7.9.2021

Ngày duyệt bài: 13.9.2021 góp phần tăng hiệu quả chữa trị cho người bệnh tăng huyết áp.

Tư khóa: Tăng huyết áp; hiệu ứng áo choàng trắng; HA lưu động 30 phút; Bệnh viện Nhật Tân.

\section{SUMMARY \\ DIAGNOSIS OF THE WHITE COAT EFFECT BY 30-MINUTE OFFICE BLOOD PRESSURE MONITORING (OBP30)}

Patients who came to the examination rooms of the Out-Patient Examination Department of Nhat Tan hospital with hypertension that the doctor thought about the white coat effect during 8 months from October 1, 2020 to May 31, 2021. The number of patients with OBP30 measured was 163 including records with at least 8 readings. Methods: Cohort. Blood Pressure Monitoring device was Norav, NBP-24 NG. Results: A total of 163 patients were recorded with full OBP30, of which 93 were female, accounting for $57 \%$. Age 14 to 86 . Mean age was $48.7 \pm 14.5$. When measuring OBP and someone showing signs of hypertension, the doctor thought that 107 people should be treated $(65.6 \%)$. After getting the results of OBP30, the doctor only prescribed antihypertensive treatment for 74 people $(45.4 \%)$, reduced 33 people, and the rate of reduction in hypertension treatment was $20.2 \%$. Conclusion: Our study shows that OPB30 reduces the effect of White Coat Effect about $20.2 \%$ of cases with identified office hypertension. Thereby, treating hypertensive patients and monitoring White Coat Effect patients will be more effective as well as reducing costs and side effects for them.

Key words: Hypertension; Office Blood Pressure (OBP), 30-MinuteOBP Monitoring (OBP30), White coat effect; Nhat Tan hospital. 


\section{I. ĐĂT VẤN ĐỀ}

Việc sử dụng các phép đo huyết áp (HA) tại buồng khám (HABK) và ngoài buồng khám (đo HA tại nhà hoặc huyết áp lưu động-HALĐ) có thể xác định những người bị tăng huyết áp (THA) áo choàng trắng $(\mathrm{ACT})$, những người chỉ tăng $\mathrm{HA}$ ở BK (không THA khi đo tại nhà hoăc khi đo bằng HALĐ) và những người bị THA ẩn giấu, ngược lại, không tăng HABK nhưng THA ngoài BK (khi đo HALĐ hoăc tại nhà). THA.ACT xảy ra khoảng 10\%-40\% đối tượng đến khám, phổ biến ở phụ nữ và ở người khồng hút thuốc. ở người quá già, tỷ lệ có thể trên $50 \%[1,2]$.

Các nghiên cứu gần đây đã cho thấy người bị THA.ACT có thể có vấn đề về tim mạch. Các đối tượng THA.ACT có nguy cơ tim mạch trung gian giữa người không THA và người THA kéo dài. Chẩn đoán cần xác nhận với các phép đo HABK và $H A$ ngoài $B K$ lặp lại nhiều lần. Nếu tổng nguy cơ tim mạch của họ thấp và không có tổn thương cơ quan gây ra THA, thì điều trị bằng thuốc có thể không được chỉ định. Tuy nhiên, những người bệnh này vẫn cần được khuyên thay đổi lối sống, do họ có thể phát triển THA kéo dài cần điều trị bằng thuốc sau này [1].

Các phép đo HA hàng ngày thường thiếu chính xác. Đo HA tại nhà thường có số liệu thấp hơn đo tại $B K$ hay tại bệnh viện nhưng thường phản ánh đúng với HA thật của NB. Tại BK, một số người bệnh bị THA do "hiệu ứng ACT". Nểu bác sĩ (BS) chỉ căn cứ vào số đo HA tại BK thì dễ đưa ra chẩn đoán THA và sẽ kê đơn thuốc ha HA, mà đôi khi với nhiều loại thuốc hạ áp. Nhứ vậy, người bệnh sẽ chịu các tác dụng phụ của thuốc và chi phí không đáng có.

Với sự ra đời của cách đo HALĐ bằng Holter HA đã giúp giải quyết vấn đề này nếu được áp dụng trong chẩn đoán THA. Đo HALĐ ngày càng được xem là tiêu chuẩn vàng trong chẩn đoán THA. Nhờ đó, các bác sĩ có thêm phương tiện để chẩn đoán loại trừ THA.ACT và điều trị đúng mức hơn.

Gần đây có một số nghiên cứu dùng máy đo HALĐ để đo HA cho người bệnh nghi ngờ có hiệu ứng $\mathrm{ACT}$ bằng cách đo liên tục trong một khoảng thời gian ngẳn giúp chẩn đoán phân biệt được THA thực và THA.ACT. Từ năm 2011, nhiểu nghiên cứu về đo HALĐ trong thời gian 30 phút có thể giảm thiểu hiệu ứng ACT và có độ lặp lại tốt hơn $[5,6]$. Sau này, một số tác giả kéo dài thời gian lưu động lên 1 giờ (Paz và cs [3], MasHeredia và cs [4]) vì cho rằng với thời gian này HALD 1 giờ có độ nhạy và độ đặc hiệu trong chẩn đoán tăng huyết áp gần với kết quả chẩn đoán với huyết áp liên tục 24 giờ ban ngày và tránh hiệu ứng $\mathrm{ACT}$ và các hiệu ứng HA khác.

Theo chúng tôi, nếu HALE் được xem là tiêu chuẩn vàng trong chẩn đoán THA và nếu cả 3 phương pháp cải tiến 30 phút, 1 giờ và 24 giờ có độ nhạy và độ đặc hiệu tương đưỡng thì nên chọn HALĐ. 30 vì đớ tổn thời gian và dễ chịu cho người bệnh cũng như cho thầy thuốc. Do đó chúng tôi dùng HALĐ.30 để tiến hành nghiên cứu này với mục tiêu xác định và loại trừ hiệu ứng THA.ACT trong chẩn đoán và điều trị bệnh THA.

\section{II. ĐỐI TƯỢNG VÀ PHƯƠNG PHÁP NGHIÊN CỨU}

Đối tượng nghiên cứu: Những người đênn khám tại các buồng khám thuộc Khoa Khám bệnh của Bệnh viện Nhật Tân, có THA mà bác sĩ khám nghĩ đến THA.ACT.

Đối tượng loại trừ: Những người không đồng thuận tham gia nghiên cứu, không thu thập đủ số liệu nghiên cứu.

Thời gian \& Địa điểm: 8 tháng, từ $1 / 10 / 2020$ cho đến $31 / 5 / 2021$; tại Bệnh viện Nhật Tân, thành phố Châu Đốc.

Cỡ mẫu nghiên cứu: Áp dụng công thức tính cõ̃ mẫu chỉ có 1 nhóm đối tượng.

$\mathrm{N}=\frac{1.96^{2} \sigma^{2}}{E^{2}}$

Trong đó độ tin cậy 95\%; $\sigma$, độ lệch chuẩn chúng tôi cho là $5 \mathrm{~mm} \mathrm{Hg}$; , tỷ lệ sai sót là $1 . \mathrm{N}$ sẽ là 96 . Số lượng người bệnh nghiên cứu của chúng tôi là 163.

Chọn mẫu: Trong tổng số 190 trường hợp được đo HALĐ.30, có 27 trường hợp bị loại, đa số $(25)$ do thời gian ghi không đủ (phải qua ít nhất 8 lần đo), 2 trường hợp thiếu bản ghi do lỗi kỹ thuật. Số bản ghi đưa vào nghiên cứu: 163 .

Phương pháp nghiên cứu: Thuần tập; theo dõi dọc người bệnh THA tại các buồng khám của Bệnh viện.

\section{Cách tiến hành:}

- Tại buồng khám BS: Khi bác sĩ BK nghi ngờ có hiệu ứng ACT ở bệnh nhân THA sẽ cho chuyển đển buồng đo holter $\mathrm{HA}$ có đủ chi tiết: tên tuổi, giới tính, mã số, ngày giờ khám, lý do khám, bệnh sử, các bệnh nền, số đo $H A$ tại $B K$, có dùng thuốc hạ HA chưa, lý do đo HALĐ.30, dự kiến điều trị như thế nào trước và sau khi có kết quả HALĐ. 30.

- Tại buồng đo HALĐ.30 do Điêu dưỡng phụ trách: Người bệnh từ buồng $B S$ chuyển tới được Điều dưỡng đo lại HA trước khi đo HALĐ.30 khoảng 10 phút; sau đó chuyển sang đo HALĐ. 30 với ít nhất 8 lần lấy kết quả vào bảng ghi. Buồng ghi có nhiệt độ khoảng $22-25^{\circ} \mathrm{C}$, thoáng khí, kín đáo. Người bệnh được đo ở tay phải với vị trí của vòng bít $2 \mathrm{~cm}$ trên hố trước trụ. Tư thế 
người bệnh: ngồi, tựa lưng, lòng bàn chân áp sát sàn, giữ vòng bít ngang tim; nghỉ ngơi 5 phút khi không có người quan sát trước khi bắt đầu đo HA. Điều dưỡng đo HA một lần đầu tiên, sau đó ra khỏi phòng. Người bệnh giữ nguyên tư thế trong lúc máy đang đo. Sau 30 phút, điều dưỡng trở lại phòng, tháo máy, in kết quả và mời bác sĩ đọc kết quả. Nếu bảng ghi bị lỗi hay <8 lần đo, sẽ bị hủy. Bảng ghi phải bỏ kết quả lần ghi đầu tiên do hay bị nhiều, còn lại 7 lần ghi, có nghĩa là đã ghi trong 30 phút.

\section{Dung cu đo HA}

Máy đo Holter HALĐ.30: Hiệu Norav, NBP24 NG, sản xuất tại Đức năm 2020 do Công ty Norav Medical Ltd., tiêu chuẩn châu Âu, CE0044.

Máy đo HA buồng khám BS: Hiệu Omron, Model JPN600, tiêu chuẩn châu Âu CE0197. Các máy đo đều có các vòng bít với kích thước khác nhau để phù hợp với các chu vi vòng cánh tay khác nhau.

Xử lý số liệu: Tất cả dữ liệu đã được nhập vào và phân tích trong SPSS (phiên bản 20). Dùng crosstabs để kiểm định các biến định tính. Dùng Paired Samples T- test để xử lý các mẫu bắt cặp, trong nghiên cứu này là lấy $\mathrm{HA}$ tâm thu (HATT) và HA tâm trương (HATTr) của 2 lần đo tại BK so với HALĐ.30. Dùng biểu đồ ROC để tìm điểm cắt của các biến định lượng, ở đây là tình trạng có tăng hay không tăng HA. Số trung bình \pm Độ lệch chuẩn (SD). Trị số $p<0,05$ được xem có ý nghĩa thống kê.

Đạo đức trong nghiên cứu: Các đối tượng được thông báo chi tiết về các nội dung và mục tiêu nghiên cứu và lấy ý kiến đồng thuận. Mọi thông tin cá nhân đều được bảo vệ.

\section{KẾT QUẢ NGHIÊN CỨU}

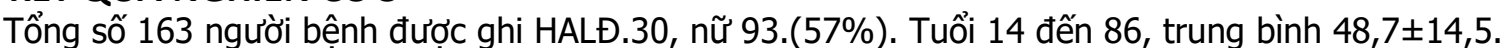

Bảng 1. So sánh HATT.TB và HATTr.TB giữa HALĐ.30 và HABK lân đo 1

\begin{tabular}{|c|c|c|c|c|c|}
\hline Danh mục & $\mathbf{n}$ & HA đo tại BK & HA đo LĐ30 & $\begin{array}{c}\text { Sai biệt HA đo } \\
\text { BK và LĐ30 }\end{array}$ & p \\
\hline HATT.TB & 163 & $155,6 \pm 25,9$ & $136,3 \pm 18,3$ & $19,3 \pm 17,5$ & 0,001 \\
\hline HATTr.TB & 163 & $94,1 \pm 12,2$ & $92,2 \pm 14,0$ & $1,9 \pm 11,9$ & 0,044 \\
\hline
\end{tabular}

Bảng 2. So sánh HATT giữa HALĐ.30 và HABK lần đo 1 ở các phân nhóm

\begin{tabular}{|c|c|c|c|c|c|c|}
\hline Danh mục & Nhóm BN & n & HATT (BK) & HATT (HALĐ.30) & Sai biệt HATT & p \\
\hline \multirow{2}{*}{ Giới } & Nữ & 90 & $153,5 \pm 22,3$ & $142,4 \pm 24,5$ & $23,4 \pm 18,7$ & 0,001 \\
& Nam & 73 & $158,3 \pm 30,1$ & $138,1 \pm 17,3$ & $20,2 \pm 19,0$ & 0,001 \\
\hline \multirow{2}{*}{ Tuổi } & $<60$ & 128 & $154,8 \pm 26,2$ & $135,6 \pm 17,2$ & $19,3 \pm 17,7$ & 0,001 \\
& $\geq 60$ & 35 & $155,9 \pm 23.9$ & $137,8 \pm 18,4$ & $18,2 \pm 16,5$ & 0,001 \\
\hline Bệnh mắc & Có & 53 & $155,9 \pm 22,4$ & $137,4 \pm 17,3$ & $19,5 \pm 17,1$ & 0,001 \\
kèm & Không & 110 & $155,4 \pm 27,6$ & $135,8 \pm 18,9$ & $19,6 \pm 17,8$ & 0.001 \\
\hline
\end{tabular}

Bệnh mắc kèm bao gồm đái tháo đường típ 2, suy thận mạn, rối loạn chuyến hóa lipid. Phân tích HATTं giữa các nhóm bệnh, không cho thây khác biệt có ý nghĩ́a thống kê. Dùng Paired Samples Ttest để so sánh HATT giữa HABK và HALĐ.30, khác biệt có ý nghĩa với $p<0,001$

Bảng 3. So sánh HATTr giữa HALĐ.30 và HABK lần đo 1 ở các phân nhóm

\begin{tabular}{|c|c|c|c|c|c|c|}
\hline $\begin{array}{c}\text { Đặc } \\
\text { trứng }\end{array}$ & $\begin{array}{c}\text { Phân } \\
\text { nhóm BN }\end{array}$ & $\mathbf{n}$ & $\begin{array}{c}\text { HATTr } \\
\text { (BK) }\end{array}$ & $\begin{array}{c}\text { HATTr } \\
\text { (HALĐ.30) }\end{array}$ & $\begin{array}{c}\text { Sai biệt } \\
\text { HATTr }\end{array}$ & p \\
\hline \multirow{2}{*}{ Giới } & Nứ & 90 & $93,7 \pm 12,6$ & $90,1 \pm 12,7$ & $3,5 \pm 11,5$ & 0,004 \\
& Nam & 73 & $94,7 \pm 11,8$ & $95,0 \pm 15,2$ & $-0,3 \pm 12,2$ & 0,838 \\
\hline \multirow{2}{*}{ Tuổi } & $<60$ & 128 & $95,3 \pm 12,4$ & $92,6 \pm 13,8$ & $2,3 \pm 11,9$ & 0,032 \\
& $\geq 60$ & 35 & $89,8 \pm 10,9$ & $89,4 \pm 14,6$ & $4,3 \pm 11,7$ & 0,830 \\
\hline Bênnh đi & Có & 53 & $94,6 \pm 12,3$ & $92,8 \pm 11,4$ & $1,7 \pm 12,0$ & 0,299 \\
kèm & Không & 110 & $93,8 \pm 11,7$ & $91,9 \pm 15,1$ & $1,9 \pm 11,9$ & 0,086 \\
\hline
\end{tabular}

Dùng Paired Samples T-test đế so sánh HATTr giữa HABK và HALĐ.30, khác biệt không có ý nghĩa với $p>0,05$.

Bảng 4. So sánh tình trạng THA sử dụng số đo HA của 3 loại đo

\begin{tabular}{|c|c|c|c|c|c|}
\hline \multirow{3}{*}{$\begin{array}{c}\text { Tình träng THA } \\
\text { dùng kết quả đo } \\
\text { HALĐ.30 }\end{array}$} & \multirow{3}{*}{$\begin{array}{c}\text { Tổng số } \\
\text { mối lần đo }\end{array}$} & \multicolumn{4}{|c|}{ Tình trạng THA do các loại đo khác } \\
\hline & & \multicolumn{2}{|c|}{ Đo tại buồng khám BS } & \multicolumn{2}{|c|}{ Điều dưỡng đo trước HALĐ.30 } \\
\hline & & Không THA & THA & Không THA & THA \\
\hline Không THA & 82( & $31(37,8 \%)$ & $51(62,2 \%)$ & $58(70,7 \%)$ & $24(29,3 \%)$ \\
\hline Tăng HA & 81 & $5(6,2 \%)$ & $76(93,8 \%)$ & $14(17,3 \%)$ & $67(82,7 \%)$ \\
\hline Cộng & & $36(22,1 \%)$ & $127(77,9 \%)$ & $72(44,2 \%)$ & $91(55,8 \%)$ \\
\hline
\end{tabular}




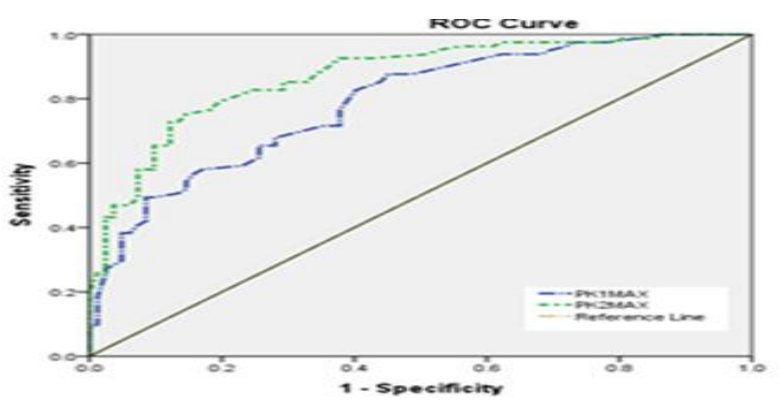

Hình 1: Biểu đồ ROC.

BK1Max: Đo HA ở BK của Bác sĩ, BK2Max: Điều dưỡng đo trước khi đo HALĐ.30.

Dùng HALĐ.30 làm "tiêu chuẩn vàng" để so sánh với lần đo 1 tại BK bác sĩ, lần thứ 2 do điều dưỡng đo 10 phút trước khi đo HALĐ.30. Hai lần đo HA tại BK có số đo cao hơn so với HALĐ.30. Nhận xét này được thể hiện qua Bảng 5 và Biểu đồ ROC-Curve: Các đường cong BK1Max và BK2Max đều nằm phía trên của đường thẳng chuẩn tạo bởi HALĐ.30

Bảng 5. Phân tích bằng biểu đồ ROC diễn tả biến thiên của các lần đo HABK

\begin{tabular}{|c|c|c|c|c|c|}
\hline $\begin{array}{c}\text { Các biến trung } \\
\text { bình }\end{array}$ & $\begin{array}{c}\text { Ngưỡng } \\
\mathbf{m m H g}\end{array}$ & $\begin{array}{c}\text { Độ nhạy } \\
\mathbf{\%}\end{array}$ & $\begin{array}{c}\text { Độ đặc hiệu } \\
\text { \% }\end{array}$ & $\begin{array}{c}\text { AUC } \\
\text { (KTC95\%) }\end{array}$ & $\mathbf{p}$ \\
\hline HATT BK lần 1 & 144,0 & 82,7 & 40,2 & $0.789(0,721-0,857)$ & 0,001 \\
\hline HATT BK lần 2 & 146,0 & 75,3 & 14,6 & $0.871(0.817-0.925)$ & 0,001 \\
\hline
\end{tabular}

Bảng 6. Lý do BS chuyến đến buồng đo HALĐ30

\begin{tabular}{|c|c|c|c|}
\hline Lý do cân đo HALĐ.30 & \multirow{2}{*}{$\mathbf{n}$} & \multicolumn{2}{|c|}{ THA.BK đo lân 1 } \\
\cline { 3 - 4 } & & Không THA & THA \\
\hline HA dao động, không ốn định & $70(42.9 \%)$ & $19(27,1 \%)$ & $51(72,9 \%)$ \\
BS nghi người bệnh bị THA.ACT & $50(31,7 \%)$ & $11(22,0 \%)$ & $39(78,0 \%)$ \\
Uống thuốc HA hay bị hạ HA & $6(3,7 \%)$ & $0(0 \%)$ & $6(100 \%)$ \\
Người bệnh bị THA lâu ngày & $37(22,7 \%)$ & $6(16,2 \%)$ & $31(83,8 \%)$ \\
\hline
\end{tabular}

Bảng 7. So sánh chênh lệch số BN thực cần điều trị THA sau đo HALĐ.30

\begin{tabular}{|c|c|c|c|}
\hline Cách đo HA & HABK bác sĩ lần 1 & HALĐ.30 & Chênh lệch \\
\hline Số người được chỉ định điêu trị THA & $107(65,6 \%)$ & $74(45,4 \%)$ & $33(20,2 \%)$ \\
\hline
\end{tabular}

Khi đo HABK, BS nghĩ rằng cần điều trị cho 107 người $(65,6 \%)$. Sau khi đo HALĐ.30, BS chỉ kê đơn điêu trị THA cho 74 người (45,4\%). Giảm 33 người (20,2\%).

\section{BÀN LUÂ̂N}

Trong thời gian 8 tháng $(1 / 10 / 2020$ cho đến 31/5/20) nhóm nghiên cứu có tất cả 190 trường hợp đo HALĐ.30, nhưng 27 trường hợp bị loại. Số bản ghi được nghiên cứu là 163 . Tổng số có 163 người bệnh được ghi HALĐ.30 đầy đủ, trong đó nữ 93 người, chiếm 57\%. Tuổi từ 14 đến 86. Tuổi trung bình là 48,7 $\pm 14,5$.

Khi so sánh HATT trung bình thấy sai biệt giữa HATT của $\operatorname{HABK}(155,6 \pm 25,9 \mathrm{~mm} \mathrm{Hg})$ và HALĐ.30 $(136,3 \pm 18,3 \mathrm{~mm} \mathrm{Hg})$, chênh lệch là $19,3 \pm 17,5$, khác biệt có ý nghĩa thống kê với $p<0,001$. Trong khi đó, Bos và cs [7] độ chênh này ở một nghiên cứu bao gồm 201 người bệnh là $22,8 \mathrm{~mm} \mathrm{Hg}$ [3]. Còn HATTr.TB giữa HABKK $(94,1 \pm 12,2)$ và HALĐ.30 $(92,2 \pm 14,0)$ cũng cho khác biệt có ý nghĩa thống kê với $p=0,044$, yếu hơn khi so sánh HATT.TB giữa 2 phương pháp đo. Nghiên cứu của Bos và cs khác biệt này lần lượt là $88,9(87,4 \pm 9, .4)$ ở HATTr.TB BK và $77,3(75,7 \pm 78,9)$ cho thấy các số liệu về HATT.TB trong nghiên cứu của chúng tổi đều cao hơn nghiên cứu của Bos và cs [7]. Độ chênh giữa 2 phép đo và HATTr.TB khác biệt của nghiên cứu chúng tôi là $1,9 \pm 11,9$, trong khi sai biệt này ở Bos và cs là $11,6(10,2-13,1)$. Khác biệt giữa HATT và HATTr giữa nghiên cứu của chúng tôi và Bos ngoài yếu tố chủng tộc còn có thể do tuổi của đối tượng trong nghiên cứu này trẻ hơn $(48,7 \pm 14,5)$ so với nghiên cứu của Bos và cs $(60,2 \pm 13,6)$.

Chúng tôi nhận thấy số đo $\mathrm{HA}$ lần đầu tại $\mathrm{BK}$ bác sĩ cho tỷ lệ THA so với tổng số người bệnh đến khám vì bệnh tim mạch là $77,9 \%$. Số đo $\mathrm{HA}$ do điều dương thực hiện 10 phút trước khi đo HALĐ.30 thây tỷ lể THA là $55,8 \%$, thấp hơn lần đo ở BK bác sĩ. Nếu lấy kết quả đo HALĐ.30 là "tiêu chuẩn vàng" có thể thấy kết quả 2 lần đo trước đó cao hơn nhiêu so với tỷ lệ THA khi đo bằng HALĐ.30 (Bảng 4, Bảng 5 và Biểu đồ 1 ). Lý do các BS ở khoa khám bệnh cho đo HALĐ.30 bao gồm: Người bệnh có HA dao động không ổn định; BS nghi ngờ người bệnh bị THA.ACT; dùng thuốc THA hay bị hạ HA; bị THA lâu ngày với các tỷ lệ lần lượt như sau: $42,9 \%, 31,7 \%, 3,7 \%$ và $22,7 \%$.

Khi mới có kết quả đo lần $1 \mathrm{HABK}$, BS nghĩ rằng cần điều trị THA cho 107 người $(65,6 \%)$ có hội chứng tim mạch. Tuy nhiên sau khi nhận được kết quả đo HALĐ.30, BS chỉ kê đơn điều trị THA cho 74 người $(45,4 \%)$, giảm 33 người, tỷ lệ giảm 20,2\%. Lý do chính của việc giảm số người được chỉ định điều trị THA được cho là do "Hiệu 
ứng THA.ACT" có trong nghiên cứu của chúng tôi. Nghiên cứu của Bos và cs [7] cho kết quả BS sẽ điêu trị THA cho $79,1 \%$ nếu chỉ dựa vào HABK, nhưng với HALĐ.30 tỷ lệ này chỉ còn $24,9 \%$, cho thấy kết quả của chúng tôi vẫn còn thấp so với nghiên cứu của Bos và cs. Lý do có thể do chúng tôi đo HABK chỉ 1- 2 lần chưa đủ để xác định HABK.

\section{KẾT LUÂ̂N}

Nghiên cứu trên 163 người tới khám bệnh của chúng tôi cho thấy cách đo HA lưu động 30 phút giúp giảm thiểu hiệu ứng tăng $\mathrm{HA}$ do thầy thuốc (tăng HA áo choàng trắng) khoảng $20,2 \%$ các trường hợp được xác định là tăng HA qua số đo lần đầu tại phòng khám. Cách đo $\mathrm{HA}$ lưu động 30 phút có thể áp dụng trong khám và điều trị cho người bệnh tăng $\mathrm{HA}$ thật, giảm thiểu gánh nặng về thời gian, chi phí và các tác dụng phụ cho người bệnh.

\section{TÀI LIÊU THAM KHẢO}

1. Unger $T$, Borghi $C$, Charchar $F$, Khan NA, Poulter NR, Prabhakaran D, Ramirez A, Schlaich M, Stergiou GS, Tomaszewski M, Wainford RD, Williams B, Schutte AE. 2020 International Society of Hypertension Global Hypertension Practice Guidelines. Hypertension. 2020;75:1334-1357

2. Williams B, Mancia G, Spiering W, Rosei
EA, Azizi M, Burnier M, Clement DL, Coca AC et al. 2018 ESC/ESH Guidelines for the management of arterial hypertension: The Task Force for the management of arterial hypertension of the European Society of Cardiology (ESC) and the European Society of Hypertension (ESH). European Heart Journal, Volume 39, Issue 33, 01 September 2018, 3021-3104

3. de Paz LG, Kostov B, Alvira-Balada MC Colungo C, García N, Roura S, Blat E, Sierra-

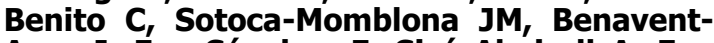
Areu J, Eva Sánchez E, Sisó-Almirall A, Eva Sanchez E. Effectiveness of a new one-hour blood pressure monitoring method to diagnose hypertension: a diagnostic accuracy clinical trial protocol. BMJ Open 2019;9:e029268.

4. Mas-Heredia M, Molés-Moliner E, Gonzálezde Paz L, et al. Validity and applicability of a new recording method for hypertension. Rev Esp Cardiol 2014;67:717-23.

5. Wel MC van der, Buunk IE, Weel $C$ van, Thien TABM, Bakx JC. A Novel Approach to Offi ce Blood Pressure Measurement: 30-Minute Office Blood Pressure vs Daytime Ambulatory Blood. Annals of Family Medicine, Vol. 9, No. 2. March/ April 2011.

6. Haan NS-de, Wel M van der, Schoenmakers G, Boudewijns S, Peer P, Weel Cv, Thien T, Bakx C. Thirty-minute compared to standardised office blood pressure measurement in general practice.British Journal of GeneralPractice, September 2011: e590-e597.

7. Bos MJ, Buis S. Thirty-Minute Office Blood Pressure Monitoring in Primary Care. Annals of Family Medicine. Vol. 15, No. 2. March/April 2017.

\section{KẾT QUẢ ĐIỀU TRI TRƯợT ĐỐT SỐNG THẮT LƯNG BẰNG PHẪU THUÂT ÍT XÂM LẤN GIẢI ÉP, GHÉP XƯƠ'NG LIÊN THÂN ĐỐT QUA LỖ LIÊN HợP}

\section{TÓM TẮT \\ Mục tiêu: Mô tả kết quả điều tri trươt đốt sống thắt lựng bằng phấu thuật ít xâm lẩn giải ép, ghép xương liên thân đốt qua î̂̃ liên hợp. Đối tướng và phương pháp: Nghiên cứu mô tả chùm ca bệnh 51 trường hợp bênh nhân trượt đốt sống thắt lưng đơn tầng được phẩu thuật ít xâm lấn giải ép, ghép xương liên thân đốt qua lố liên hợp tai khoa Phẫu thuật cột sống, Bệnh viện Hữu nghị Việt Đức từ 01/2019 - 12/2020. Kết quả: 51 bệnh nhân (11 nam, 40 nữ),}

${ }^{1}$ Đại học Y Hà Nội

${ }^{2}$ Bềnh viền Hữu nghi Viêt Đức

Chịu trách nhiệm chính: Phạm Hồng Phong

Email: drphamhongphong@gmail.com

Ngày nhận bài: 12.7.2021

Ngày phản biên khoa hoc: 30.8.2021

Ngày duyệt băi: 14.9.2021
Phạm Hồng Phong1, Nguyễn Lê Bảo Tiến ${ }^{2}$, Vũ Văn Cường ${ }^{2}$, Võ Văn Thanh ${ }^{1,2}$

tuổi trung bình là 47,9 $\pm 12,9$ (từ 15 đến 72) đã được phẫu thuâat ít xâm lấn giải ép, ghép xương liên thẩn đốt qua lổ liên hợp. Kết quả xa sau mổ được đánh giá theo tiêu chuẩn MacNab tại thời điểm 12 tháng sau mổ $44 / 51$ bênh nhân khám lại $(86,3 \%)$ : rất tốt: 28 $(63,6 \%)$, tốt: $14(31,8 \%)$, khá: $2(4,6 \%)$, xấu: 0 $(0,0 \%)$. Đánh giá cải thiện triệu chứng lâm sàng sau mổ tại thời điểm khám lại cuổi cùng: điểm đau lưng VAS (Visual Analogue Scale) trước mổ 6,22 $\pm 1,06$, sau mổ 12 tháng $1,89 \pm 1,50$, điểm đau chân VAS trước mổ $5,90 \pm 1,40$, sau mổ 12 tháng $1,25 \pm 1,50$, ODI (Oswestry Disability Index) trước mổ 49,41 $\pm 8,0$, ODI sau mổ 12 tháng $15,18 \pm 11,58$. Đánh giá mức độ liền xương theo Bridwell tại thới điểm sau mổ 12 tháng, tỷ lệ liên xương đạt $97,8 \%$. Biến chứng trong mổ: tổn thương rễ 2 trường hợp, chiếm 3,9\%. Kết luâan: Phẫu thuật ít xâm lấn giải ép, ghép xương liên thẩn đốt qua lố liên hợp là một phương pháp an toàn và hiệu quả trong điều trị TĐS thắt lưng đơn tâng. 